\title{
A Fragmentation Study of Di-Acidic Mycosporine-like Amino Acids in Electrospray and Nanospray Mass Spectrometry
}

\section{Karina H. M. Cardozo, ${ }^{a, b, \#}$ Ricardo Vessecchi, ${ }^{c}$ Sérgio E. Galembeck, ${ }^{c}$ Thais Guaratini, ${ }^{a, b}$ Paul J. Gates, ${ }^{b}$ Ernani Pinto, ${ }^{d}$ Norberto P. Lopes ${ }^{*, e}$ and Pio Colepicolo ${ }^{a}$}

\author{
anstituto de Química de São Paulo, Universidade de São Paulo, 05508-900 São Paulo-SP, Brazil \\ ${ }^{b}$ School of Chemistry, University of Bristol, Cantock's Close, Bristol, BS8 1TS, United Kingdom \\ ${ }^{c}$ Departamento de Química, Faculdade de Filosofia Ciências e Letras de Ribeirão Preto, \\ Universidade de São Paulo, 14040-901 Ribeirão Preto-SP, Brazil
}

${ }^{d}$ Departamento de Análises Clínicas e Toxicológicas, Faculdade de Ciências Farmacêuticas, Universidade de São Paulo, 05508-900 São Paulo-SP, Brazil

eDepartamento de Física e Química, Faculdade de Ciências Farmacêuticas de Ribeirão Preto, Universidade de São Paulo, 14040-903 Ribeirão Preto-SP, Brazil

\begin{abstract}
No presente estudo, duas micosporinas (MAAs) contendo um segundo ácido carboxílico foram submetidas à fragmentação em eletrospray e nanospray em diferentes equipamentos. Em contraste com resultados anteriores, a eliminação de radical metila no modo positivo de análise foi um processo minoritário de fragmentação. Neste trabalho apresentamos também a via de fragmentação destas substâncias em modo negativo e cálculos teóricos para caracterizar os sítios de protonação.

Two mycosporine (MAAs), containing an extra acid function, were analyzed by nanospray and electrospray ionization tandem mass spectrometry. In contrast to the previous studies it is demonstrated that no significant characteristic methyl radical loss occurred in positive mode. The fragmentation pathway in negative mode was also proposed in this work, along with theoretical calculations to characterize the site of protonation.
\end{abstract}

Keywords: mycosporine, nanoESI-MS/MS, ESI-MS/MS, natural products, algae

\section{Introduction}

Mycosporine-like amino acids (MAAs) are a group of chemically related, water soluble compounds responsible for UV photoprotection in a diverse range of organisms including invertebrates, fish, bacteria, cyanobacteria, micro- and macroalgae. ${ }^{1-3}$ These compounds are chemically characterised by the presence of either a cyclohexenone or cyclohexenimine chromophore conjugated with a substituent nitrogen of an amino acid, amino alcohol or amino group (Figure 1). ${ }^{1}$ MAAs normally show a strong UV absorption between 310 and $360 \mathrm{~nm}$ with high molar extinction coefficients. These characteristics indicate a possible photoprotective role that has been demonstrated

*e-mail: npelopes@fcfrp.usp.br

"Present address: Fleury Medicina e Saúde, Av. General Valdomiro de Lima 508, 04344-070 São Paulo-SP, Brazil

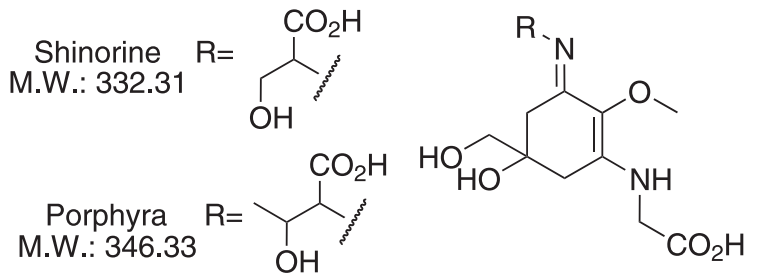

Figure 1. The chemical structure of the compounds analysed.

in a number of studies ${ }^{4-7}$ and for the economic interest of pharmaceutical companies. In addition to a UV protective function, it has been suggested that MAAs also have antioxidant activity, ${ }^{8}$ osmotic functions, ${ }^{9}$ and regulatory role in reproduction. ${ }^{10}$ More than 20 MAAs have so far been characterised and identified in aquatic environments and this number is increasing with the development and application of more efficient and sensitive methodologies such as high performance liquid chromatography (HPLC) and mass spectrometry. ${ }^{11-13}$ 
Tandem mass spectrometry (MS/MS) fragmentation studies in positive ion mode along with UV spectra are the normal tools for the structure elucidation for the new derivatives of MAAs. ${ }^{12-18}$ The increased application of mass spectrometry to the analysis of natural products is related to the improved quality of the structural information produced by elucidation of fragmentation patterns, mechanisms and pathways. ${ }^{19-20}$ Previously, several studies have focussed on the fragmentation of some MAAs showing a highly characteristic loss of mass 15 when analysed by positive mode ESI-MS/MS, in addition to a complex fragmentation pathway. ${ }^{13,15,17}$ Recently, a theoretical and FT-ICR-MS mass spectrometry study showed that the elimination of mass 15 is due to a radical processes taking place at the methoxyl group link to a unsaturated carbon..$^{18}$ Attempts to obtain spectra in negative mode were not successful. ${ }^{17}$

In the last few years, nanospray ionisation (nanoESI) is beginning to increase in importance, especially with the development of automated systems using 'chips' (arrays of uniform nanospray needles that are used only once to avoid contamination). ${ }^{21}$ NanoESI offers the possibility of improved sensitivity and lower sample consumption over conventional ESI for the analysis of natural products. ${ }^{22}$ This is especially important for the study of extracts from biological and medicinal sources when often only a very small amount of material is available.

In 'chip based' nanoESI, the analyte solution is sprayed from a conducting pipette tip pressed against the rear of a chip using a small gas pressure and much lower voltages to create the spray. Recently, analysis of some natural antioxidants (retinoids ${ }^{23,24}$ and carotenoids ${ }^{25,26}$ ) using 'chip based' technology showed differences in the ionisation behavior when compared with conventional ESI. This increases the possibilities for structure elucidation at low sample amounts as new fragmentation routes are made available by controlling the types of ions being formed. Based upon these previous studies, the purpose of this work is to compare the ionisation of MAAs in negative and positive mode nanoESI and establish, for the first time, a sound basis for the mechanism of the fragmentation of MAA anions.

\section{Experimental}

\section{Chemicals}

All solvents used were HPLC grade (Tedia, J. Baker and Fisher). Water was purified using a Milli-Q system (Millipore, Bedford, MA, USA). Trifluoroacetic acid (99.9\%) was purchased from Aldrich. Galena Química e Farmacêutica Ltda/Brazil kindly supplied the standards of shinorine and porphyra-334 (product Helioguard ${ }^{\circledR} 365$ Porphyra umbilicalis extracts)

\section{Instrumentation}

Nanospray ionisation analyses were performed on two quadrupole-time of flight hybrid instruments: (a) an UltrOTOF-Q (Bruker Daltonics, Billerica, MA) using Tip ${ }^{\mathrm{TM}}$ Emittek (glass tip capillaries working with $500 \mathrm{~V}$ ) or (b) a QStar-XL (Applied Biosystems, Warrington, UK) using a Nanomate HD automatic 'chip based' nanospray system (Advion Biosciences, Norwich, UK). The Nanomate was set for $5 \mu \mathrm{L}$ of solution to be aspirated and sprayed through a Nanomate 400 chip at $1.45 \mathrm{kV}$, with a nitrogen back pressure of 0.4 psi. On both instruments, the ion source gas and curtain gas were nitrogen.

Electrospray ionisation analyses were performed on five instruments: (a) an Apex 4 7.0 Tesla Fouriertransform ion-cyclotron resonance mass spectrometer (Bruker Daltonics, Billerica, MA, USA). Samples were directly infused into the Apollo electrospray source from a syringe pump at $100 \mu \mathrm{L} \mathrm{h}^{-1}$. Analyses were performed at a capillary voltage, of $4600 \mathrm{~V}$ and capillary exit potential of $200 \mathrm{~V}$ (except were indicated otherwise). The $\mathrm{N}_{2}$ drying gas temperature was $200{ }^{\circ} \mathrm{C}$. A mixture of PEG grades was used as an external calibrant for accurate-mass ESI analysis; (b) on a quadrupole-time of flight instrument (UltrOTOF-Q, Bruker Daltonics, Billerica, MA). The analyses were performed in positive ion ESI mode at a capillary voltage of $3400 \mathrm{~V}$ and $\mathrm{N}_{2}$ drying gas temperature of $180^{\circ} \mathrm{C}$. NaTFA $10 \mathrm{mmol} \mathrm{L}{ }^{-1}$ was used as a standard for internal and external calibration; (c) on a QStar-XL quadrupole-time-of-flight instrument (Applied Biosystems, Warrington, UK); (d) on a Quattro-LC triple quadrupole mass spectrometer (Micromass, Manchester, UK); (e) on an Esquire HCT ion trap instrument (Bruker Daltonics, Billerica, MA, USA) using a syringe pump (Cole-Parmer, Vernon Hills, IL, USA). Ion trap analyses were performed using nitrogen as the nebulising and drying gas and helium as the bath gas $\left(4 \times 10^{-6} \mathrm{mbar}\right)$.

\section{Theoretical calculations}

All calculations were performed in Gaussian $03^{27}$ suite of programs using the B3LYP/6-31+G(d,p) model..$^{28,29}$ The geometries of neutral and protonated species were optimised and the potential energy surface minima were indicated by analysis of vibrational frequencies. The gasphase basicity and proton affinity were calculated via a protonation reaction, using Gibbs energies and enthalpies, respectively. ${ }^{30}$ 


\section{Results and Discussion}

Mycosporine-like amino acids with one acidic function were previously analysed by positive mode ESI sequential mass spectrometry (at high-resolution and accurate-mass). The loss of a methyl radical by the homolytic cleavage of the $\mathrm{O}-\mathrm{C}$ bond was observed to be the preferred fragmentation pathway. ${ }^{13,17,18}$ This characteristic loss was thoroughly studied by a range theoretical calculations and the homolytic cleavage was found to be dependent on the weakening of the O-C bond. This cleavage is directly affected by the protonation site with the radical elimination occurring from the most unstable conformer..$^{18}$ In this study, we have analysed the effect that the presence of a second acidic function in the side chain has on the preferred fragmentation pathways and to pinpoint any differences observed. Figure 2 shows the product ion spectrum of porphyra-334 (precursor ion $\mathrm{m} / \mathrm{z}$ 347) obtained from a range of instruments. The spectra clearly show the occurrence of the radical fragmentation route (to product ion $\mathrm{m} / \mathrm{z} 332$ ), but at very low intensity in all instruments used (with a range of different ESI source designs, including nanoESI). Shinorine exhibits the same result as porphyra-334, which differs to those previously obtained for the mono acidic MAAs where the radical elimination mechanism is the major fragmentation pathway. However, the $\mathrm{MS}^{3}$ spectra (ion trap) of the di-acidic MAA (fragmentation of $\left[\mathrm{M}+\mathrm{H}-\mathrm{CO}_{2}\right]^{+}$) shows an intense loss of the methyl radical (Figure 2, spectrum A'). This result indicates that the presence of the two acidic functions changes the driving force for the fragmentation with a neutral elimination of $\mathrm{CO}_{2}$ being the predominant first step with all instrument set-ups. To confirm this theory, MAAs with two carboxylic acid functions were submitted to theoretical computational analysis to define the site of protonation. As described, our previous results were based on topologic analysis of electronic density, gas-phase basicity and bond order for each protonated conformer. The imine nitrogen was indicated as the most basic site. However, the most reactive ion occurs by protonation on the vinyl carbon. In order to know the protonation site of shinorine, we have calculated its gas-phase basicity and proton affinity. These results are in agreement with our previous studies; where the less energetic ion occurs by protonation on the imine nitrogen whose gas-phase basicity is $247.32 \mathrm{kcal} \mathrm{mol}^{-1}$ (Figure 3). This data indicates that the presence of the second carboxylic acid effects the protonation site leading to an increased $\mathrm{CO}_{2}$ elimination. This elimination reduces the internal ion energy and results in the observed intensity of the methyl radical elimination route. These observations suggest that the analytical methodology (such as quantification) based on protonated molecules and radical fragmentation route is not always a good choice for all MAAs. However, the selection of $\mathrm{MS}^{3}$ from $[\mathrm{M}+\mathrm{H}-15]^{+}$is still a good option for the screening of extracts which may contain MAAs. A
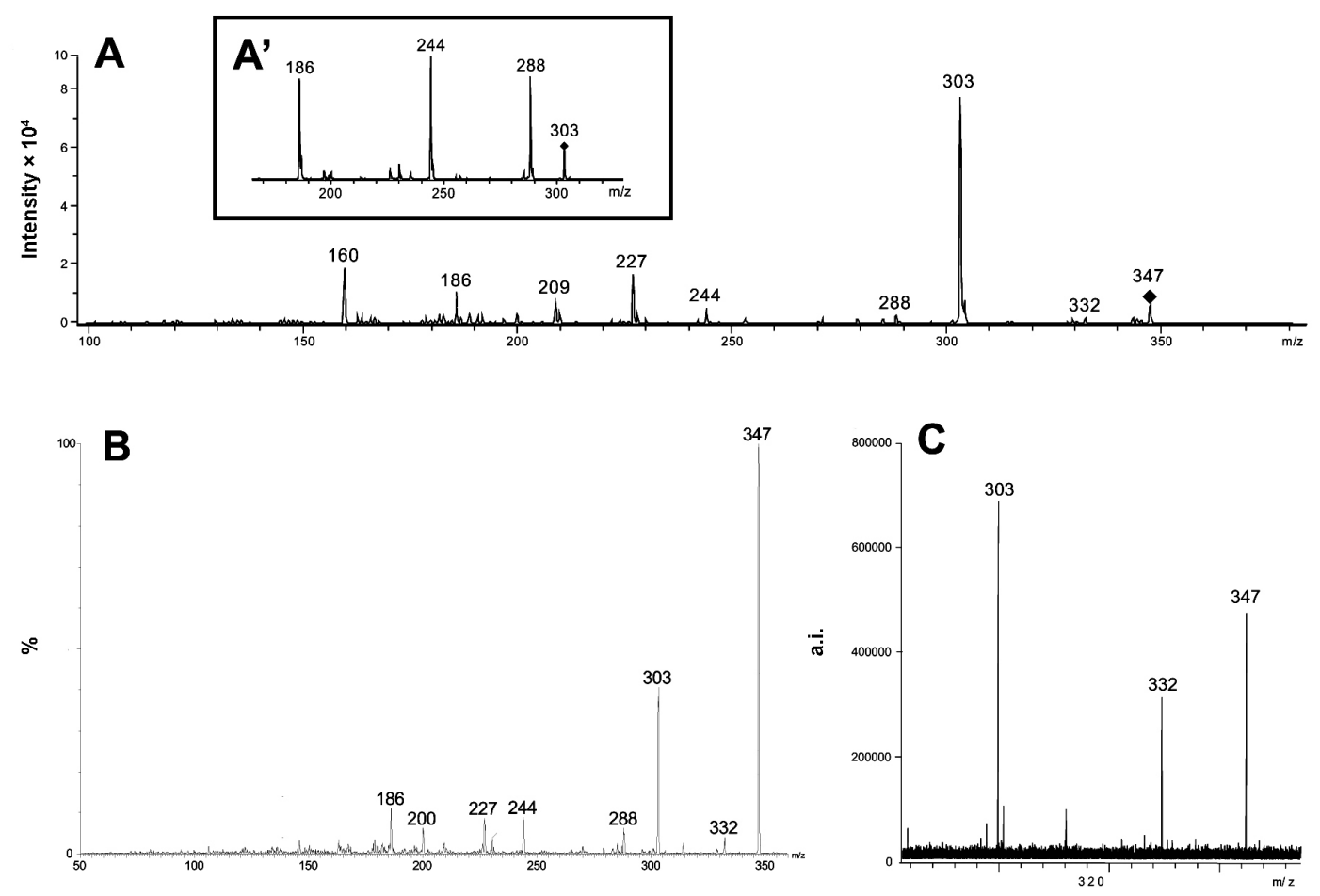

Figure 2. Positive ion ESI spectra of Porphyra-334 ( $\mathrm{m} / \mathrm{z}$ 347). A) ion trap $\mathrm{MS}^{2}$ spectra of ion $\mathrm{m} / \mathrm{z} 347$; A') ion trap MS ${ }^{3}$ spectra of ion $\mathrm{m} / \mathrm{z} 303$; B) Q-Q MS/MS of ion $m / z$ 347; C) FT-ICR MS ${ }^{2}$ spectra of ion $m / z 347$. 


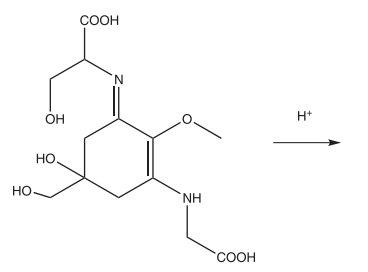

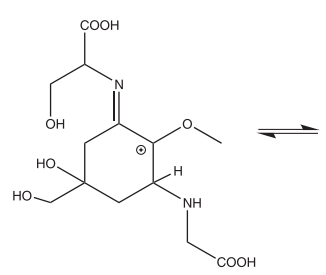

200.32

205.18<smiles>COC1C(=NC(CO)CO)CC(O)(CO)CC1NCO</smiles>

211.47
219.00<smiles>CCOC(O)CN=C1CC(O)(CO)CC(NCO)=C1OC</smiles>

247.32

Figure 3. The structure of protonated species for Shinorine. Bold values indicate the gas-phase basicity and italic values the proton affinity. All values as in $\mathrm{kcal} \mathrm{mol}^{-1}$.
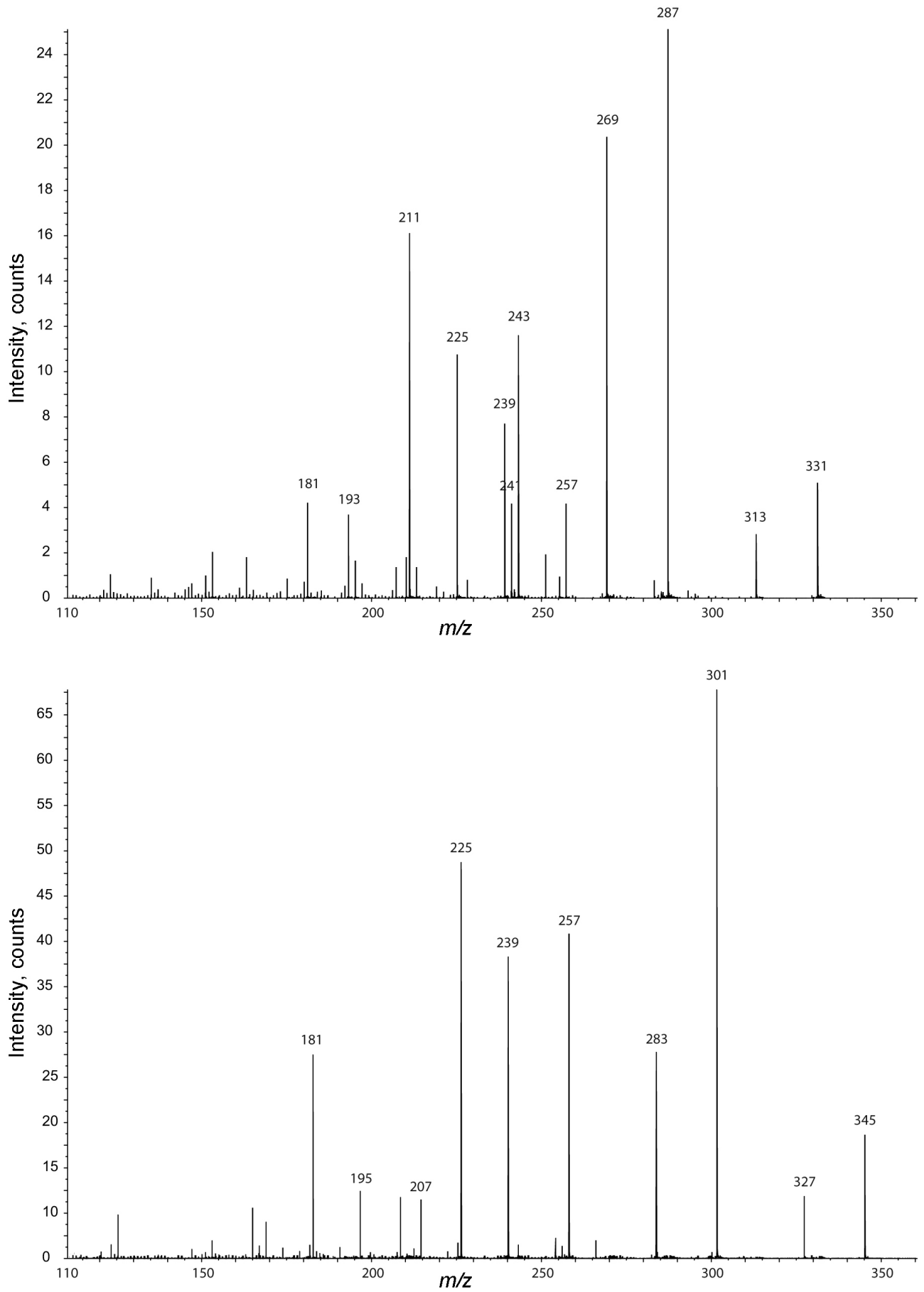

Figure 4. Negative ion nanoESI spectra of Shinorine and Porphyra-334. 
previous study with the ionophore monensin A, showed significantly different fragmentation intensities between MS/MS with ESI and nanoESI, ${ }^{31}$ but all of the experiments with the MAAs show similar behaviour in both nanoESI and ESI analysis with no significant differences being observed.

As expected, analysis in negative ion mode (Figure 4) showed no radical elimination. Considering that in the positive ion mode, the bond cleavage was observed to be dependent of the protonation site that weakens the $\mathrm{C}-\mathrm{O}$ bond, another driving force must govern the fragmentation pathways in negative ion mode. Detailed analyses suggest that the carboxylic acid function may lose the proton, which causes an increase of electron density that is stabilised by resonance. Scheme 1 represents the proposed fragmentation pathway for shinorine $(\mathrm{R}=\mathrm{H})$ and porphyra-334 $\left(\mathrm{R}=\mathrm{CH}_{3}\right)$. Product ion spectra of both shinorine and porphyra-334 produced initial $\mathrm{CO}_{2}$ eliminations followed by various combinations of $\mathrm{H}_{2} \mathrm{O}$ and/or $\mathrm{CO}_{2}$ losses. After the elimination of $\mathrm{H}_{2} \mathrm{O}$ and $\mathrm{CO}_{2}$ from the side chains, all the resultant ions must keep the negative charge on the more acidic positions. Based on this observation we expected to have the charge on the alkoxy groups, and these two possibilities must produce different terminal ions. It is proposed that the shinorine product ions $(\mathrm{m} / \mathrm{z} 225$ and 243) can go on to lose methanol (producing the ions $m / z 193$ and 211 , respectively) in opposition to the isomeric structure with the charge on

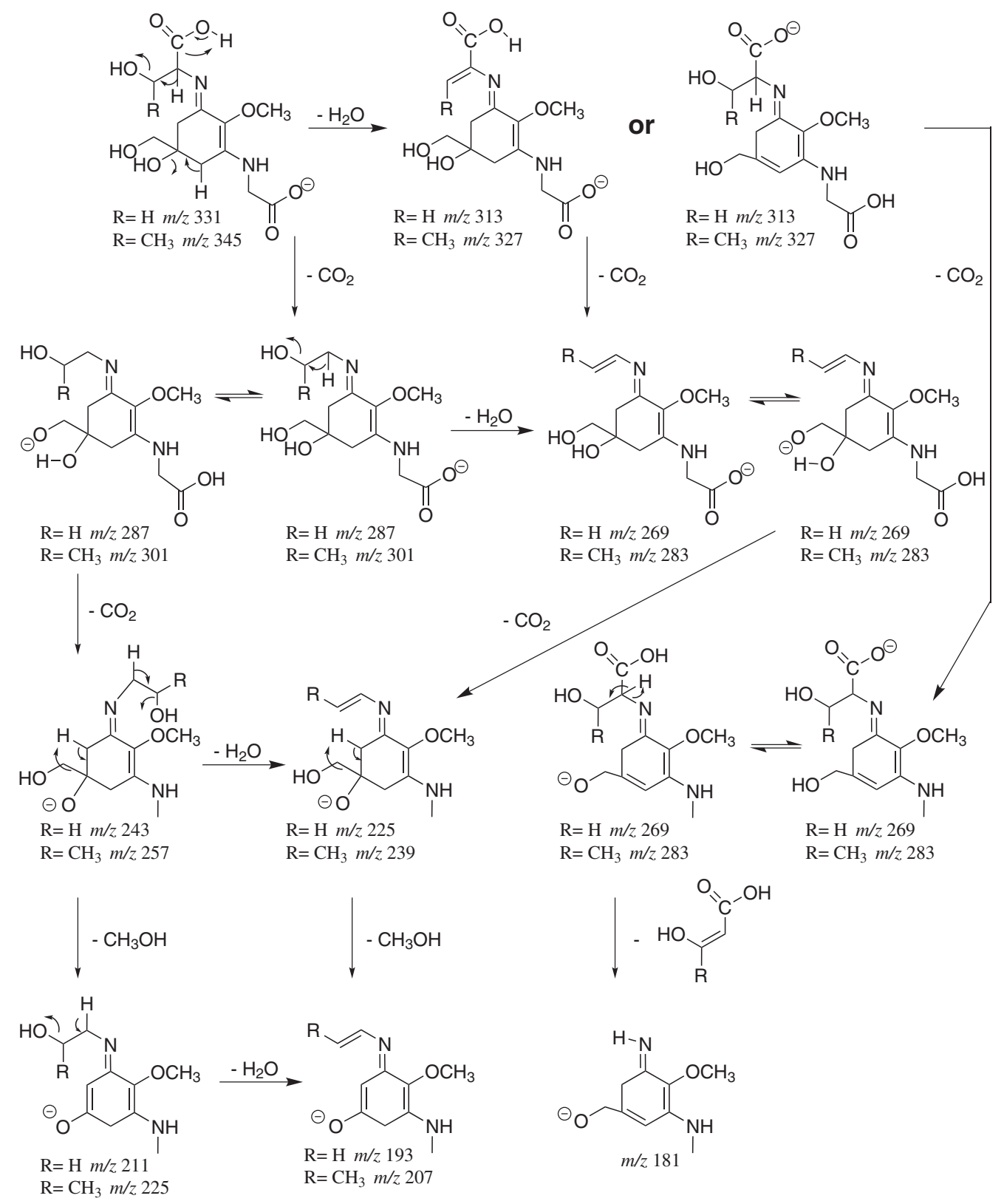

Scheme 1. The proposed fragmentation mechanism of Shinorine $(\mathrm{R}=\mathrm{H})$ and Porphyra-334 $\left(\mathrm{R}=\mathrm{CH}_{3}\right)$ in negative ion mode. 

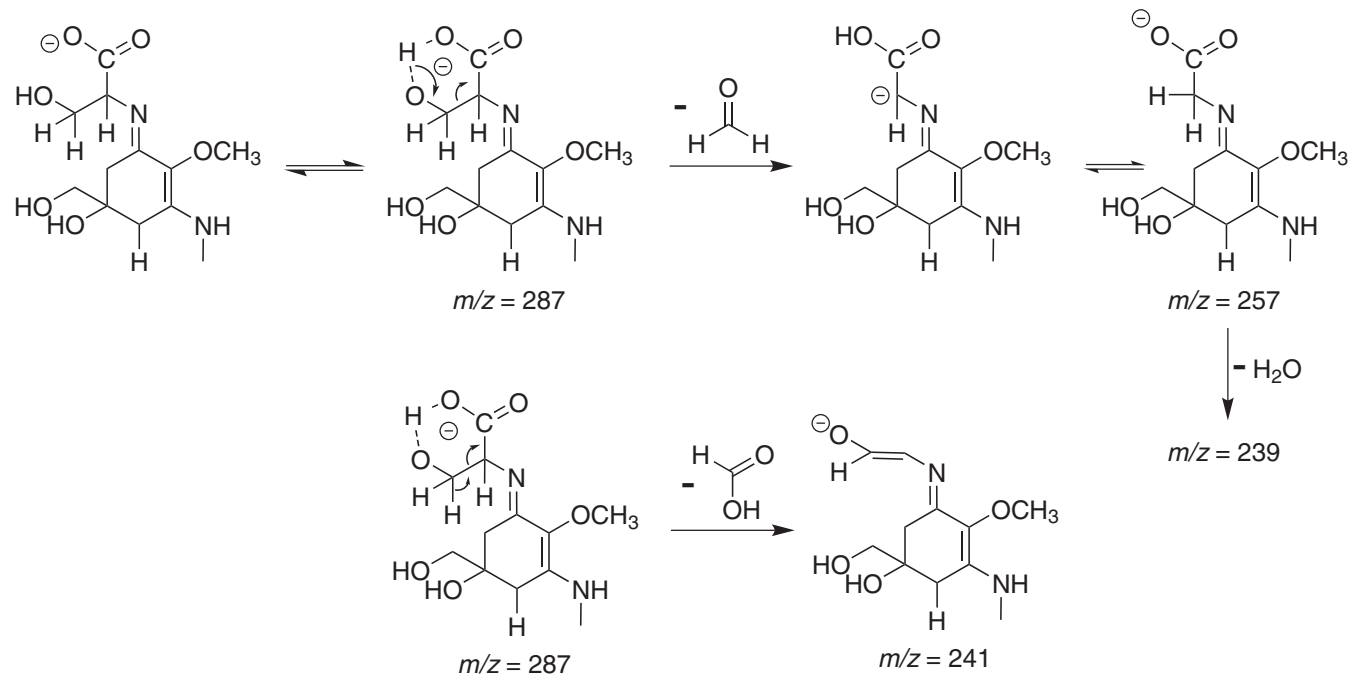

$m / z=239$

Scheme 2

the other neighbouring oxygen atom that will produce the ion $m / z$ 181. The same loses occur for porphyra-334. Careful analyses of the porphyra-334 and shinorine spectra indicate the presence of an additional fragmentation pathway for shinorine (Scheme 2). After the loss of a proton from the carboxylic acid function, the charge can be stabilised through assistance of the neighboring hydroxyl group. The non-substitution on the carbinolic carbon allows the loss of a formaldehyde neutral followed by water on one side or loss of a formic acid neutral on the other side of the bridge. These simple neutral losses may provide some further information about the side chain for theses MAAs with carboxylic acid on the side chain.

\section{Conclusions}

These results indicate that the presence of a second carboxylic acid function significantly reduces the intensity of the observed product ions from the radical methyl cleavage in positive mode MS/MS. As expected, in the negative ion mode, the radical fragmentation pathway does not occur. Taken together, these results confirm the importance of careful selection of the product ions used for analytical protocols for the analysis of crude extracts containing MAAs where the presence of the second acid function may change the fragmentation behavior and the classical analysis of loss of methyl radical may lead to the wrong conclusions during screening for MAAs.

\section{Acknowledgments}

The authors thank FAPESP (Fundação de Amparo à Pesquisa do Estado de São Paulo, 05/01572-1,
01/13482-6 and 03/08735-8), CAPES (Coordenação de Aperfeiçoamento de Pessoal de Nível Superior), CNPq and CNPq-Millenium (Conselho Nacional de Desenvolvimento Científico e Tecnológico) for research funding and financial support.

\section{References}

1. Bandaranayake, W. M.; Nat. Prod. Rep. 1998, 15, 159.

2. Dunlap, W. C.; Shick, J. M.; J. Phycol. 1998, 34, 418.

3. Groniger, A.; Sinha, R. P.; Klisch, M.; Hader, D. P.; J. Photochem. Photobiol., B 2000, 58, 115.

4. Carreto, J. I.; Carignan, M. O.; Daleo, G.; De Marco, S. G.; J. Plankton Res. 1990, 12, 909.

5. Neale, P. J.; Banaszak, A. T.; Jarriel, C. R.; J. Phycol. 1998, 34, 928.

6. Shick, J. M.; Dunlap, W. C.; Annu. Rev. Physiol. 2002, 64, 223.

7. Klisch, M.; Häder, D. P.; J. Photochem. Photobiol., B 2000, 55, 178.

8. Dunlap, W. C.; Yamamoto, Y.; Comp. Biochem. Physiol., Part B: Biochem. Mol. Biol. 1995, 112, 105.

9. Oren, A.; Geomicrobiol. J. 1997, 14, 231.

10. Bandaranayake, W. M.; Des Rocher, A.; Mar. Biol. 1999, 133, 163.

11. Carreto, J. I.; Carignan, M. O.; Montoya, N. G.; Mar. Biol. 2005, 146, 237.

12. Volkmann, M.; Gorbushina, A. A.; Kedar, L.; Microbiol. Lett. 2006, 258, 50.

13. Cardozo, K. H. M.; Carvalho, V. M.; Pinto, E.; Colepicolo, P.; Rapid Commun. Mass Spectrom. 2006, 20, 253.

14. Whitehead, K.; Karentz, D.; Hedges, J. I.; Mar. Biol. 2001, 139, 1013.

15. Whitehead, K.; Hedges, J. I.; Mar. Chem. 2002, 80, 27. 
16. Volkmann, M.; Whitehead, K.; Rütters, H.; Rullkötter, J.; Gorbushina, A. A.; Rapid Commun. Mass Spectrom. 2003, 17, 897.

17. Whitehead, K.; Hedges, J. I.; Rapid Commun. Mass Spectrom. 2003, 17, 2133.

18. Cardozo, K. H. M.; Vessecchi, R.; Carvalho, V. M.; Pinto, E.; Gates, P. J.; Colepicolo, P.; Galembeck, S. E.; Lopes, N. P.; Int. J. Mass Spectrom. 2008, 273, 11.

19. Lopes, N. P.; Stark, C. B. W.; Hong, H.; Gates, P. J.; Staunton, J.; Rapid Commun. Mass Spectrom. 2002, 16, 414.

20. Fonseca, T.; Lopes, N. P.; Gates, P. J.; Staunton, J.; J. Am. Soc. Mass Spectrom. 2004, 15, 325.

21. Schultz, G. A.; Corso, T. N.; Prosser, S. J.; Zhang, S.; Anal. Chem. 2000, 72, 4058.

22. Wilm, M.; Mann, M.; Anal. Chem. 1996, 68, 1.

23. Guaratini, T.; Vessecchi, R. L.; Lavarda, F. C.; Campos, P. M. B. G. M.; Naal, Z.; Gates, P. J.; Lopes, N. P.; Analyst 2004, 129, 1223.

24. Guaratini, T.; Gates, P. J.; Cardozo, K. H. M.; Campos, P. M. B. G. M.; Colepicolo, P.; Lopes, N. P. Eur. J. Mass Spectrom. 2006, $12,71$.

25. Guaratini, T.; Vessecchi, R.; Pinto, E.; Colepicolo, P.; Lopes, N. P.; J. Mass Spectrom. 2005, 40, 963.

26. Guaratini, T.; Gates, P. J.; Pinto, E.; Colepicolo, P.; Lopes, N. P.; Rapid Commun. Mass Spectrom. 2007, 21, 3842.

27. Gaussian 03, Revision C.02; Frisch, M. J.; Trucks, G. W.; Schlegel, H. B.; Scuseria, G. E.; Robb, M. A.; Cheeseman, J. R.; Montgomery, Jr., J. A.; Vreven, T.; Kudin, K. N.; Burant, J. C.; Millam, J. M.; Iyengar, S. S.; Tomasi, J.; Barone, V.;
Mennucci, B.; Cossi, M.; Scalmani, G.; Rega, N.; Petersson, G. A.; Nakatsuji, H.; Hada, M.; Ehara, M.; Toyota, K.; Fukuda, R.; Hasegawa, J.; Ishida, M.; Nakajima, T.; Honda, Y.; Kitao, O.; Nakai, H.; Klene, M.; Li, X.; Knox, J. E.; Hratchian, H. P.; Cross, J. B.; Bakken, V.; Adamo, C.; Jaramillo, J.; Gomperts, R.; Stratmann, R. E.; Yazyev, O.; Austin, A. J.; Cammi, R.; Pomelli, C.; Ochterski, J. W.; Ayala, P. Y.; Morokuma, K.; Voth, G. A.; Salvador, P.; Dannenberg, J. J.; Zakrzewski, V. G.; Dapprich, S.; Daniels, A. D.; Strain, M. C.; Farkas, O.; Malick, D. K.; Rabuck, A. D.; Raghavachari, K.; Foresman, J. B.; Ortiz, J. V.; Cui, Q.; Baboul, A. G.; Clifford, S.; Cioslowski, J.; Stefanov, B. B.; Liu, G.; Liashenko, A.; Piskorz, P.; Komaromi, I.; Martin, R. L.; Fox, D. J.; Keith, T.; Al-Laham, M. A.; Peng, C. Y.; Nanayakkara, A.; Challacombe, M.; Gill, P. M. W.; Johnson, B.; Chen, W.; Wong, M. W.; Gonzalez, C.; and Pople, J. A.; Gaussian, Inc., Wallingford CT, 2004, 2866.

28. Becke, A. D.; J. Chem. Phys. 1993, 98, 5648.

29. Lee, C.; Yang, W.; Parr, R. G.; Phys. Rev. B: Condens. Matter Mater. Phys. 1988, 37, 785.

30. Vessecchi, R.; Galembeck, S. E.; Lopes, N. P.; Nascimento, P. G. B. D.; Crotti, A. E. M.; Quim. Nova 2008, 31, 840.

31. Souza-Junior, J. N.; Lopes, N. P.; Gates, P. J.; Eur. J. Mass Spectrom. 2007, 13, 191.

Received: November 26, 2008 Web Release Date: September 4, 2009

FAPESP helped in meeting the publication costs of this article. 